\title{
Age of Salpingo-Oophorectomy and Risk of Peritoneal Carcinomatosis in Patients with a BRCA Mutation
}

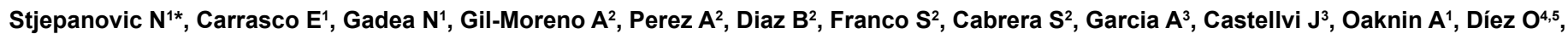
Bonache $\mathbf{S}^{4,5}$, Gutiérrez-Enríquez $\mathrm{S}^{4,5}$, Vilaro $\mathbf{M}^{5}$ and Balmaña $\mathrm{J}^{1,5}$

${ }^{1}$ Department of Medical Oncology, Vall d'Hebron Hospital, Universitat Autonoma de Barcelona, Spain

${ }^{2}$ Department of Gynecology, Vall d'Hebron Hospital, Universitat Autonoma de Barcelona, Spain

${ }^{3}$ Department of Pathology, Vall d'Hebron Hospital, Universitat Autonoma de Barcelona, Spain

${ }^{4}$ Department of Oncogenetics, Vall d'Hebron Hospital, Universitat Autonoma de Barcelona, Spain

${ }^{5}$ Vall d'Hebron Institute of Oncology (VHIO), Spain

\begin{abstract}
Background: Women with BRCA1/2 germline mutations who undergo bilateral salpingo-oophorectomy (BSO) are left with a residual risk of peritoneal serous carcinoma (PSC). We aimed to identify the incidence and risk factors for the development of PSC after BSO in BRCA1/2 mutation carriers.

Methods: One-hundred-seventeen BRCA1/2 mutation carriers who underwent BSO were evaluated for further development of PSC. The BSO specimens were evaluated for occult Fallopian tube carcinoma (FTC), ovarian carcinoma (OVC) and serous tubal intraepithelial carcinoma (STIC) in all patients. P53-signature was available in 58 patients. Clinical data was obtained from patients' charts. We calculated the association between clinical, pathological and molecular risk factors of PSC after BSO.
\end{abstract}

Results: Analysis of BSO specimens revealed occult FTC in 1 woman ( $0.8 \%)$, STIC in 2 women (1.7\%), and 6/58 women $(10.3 \%)$ had a positive "p53 signature". Older age at menopause $(p=0.007)$ and shorter oral contraceptive use ( $p<0.001)$ were associated with FTC and STICs. The incidence of PSC after BSO was $1.7 \%$ (two patients). Both were BRCA2 mutation carriers and one had a history of STIC. The only risk factor identified for PSC after BSO was older age at surgery (63.5 years for patients with PSC vs. 48.6 years for patients without PSC, $p<0.001$ ).

Conclusions: The incidence of PSC after BSO in our series is $1.7 \%$ and it is associated with an older age at BSO. Earlier menopause and oral contraceptive use seem to be associated with a decrease in the prevalence of occult FTC and STICs.

Keywords: BRCA; Bilateral salpingo-oophorectomy; Peritoneal serous carcinoma; Serous tubal intraepithelial carcinoma; p53-signature

\section{Introduction}

Women carrying a BRCA1 or BRCA2 germline mutation are at increased risk of developing ovarian carcinoma (OVC), Fallopian tube carcinoma (FTC) and peritoneal serous carcinoma (PSC) [1]. The estimated average cumulative risk of ovarian cancer (which generally includes FTC and PSC) to age 70 years in BRCA1 and BRCA2 mutation carriers is estimated to be $40 \%$ and $18 \%$, respectively [2]. The mean age of diagnosis of ovarian cancer in mutation carriers is 53 years for BRCA 1 and 59 years for BRCA2 [3]. Although frequent screening with serum CA-125 and transvaginal ultrasound monitoring is recommended in these patients [4,5], its efficacy is controversial because of finding advanced stage tumors when eventually diagnosed [6,7]. Therefore, the frequency of CA-125 and transvaginal ultrasound assessment is currently being reviewed [8] and bilateral salpingo-oophorectomy (BSO) is being recommended as the most efficient risk reduction strategy in this population, with a risk reduction for OVC and FTC in the range of $80-86 \%$ [9-12]. Despite the prophylactic surgery, cases of PSC have been reported after BSO with a residual risk of between $1 \%$ and $4.3 \%[1,10,13]$.

There is currently debate about the pathogenesis of high-grade serous carcinomas of the ovary, Fallopian tube, and peritoneum, which may help lead to understanding the residual risk of PSC after BSO in BRCA mutation carriers. The biological and pathological similarities of these three types of tumor support the hypothesis of a common molecular pathogenesis. The fimbria has been proposed as a possible origin $[14,15]$ and two non-invasive precursor lesions have been described; serous tubal intraepithelial carcinoma (STIC) and the "p53 signature" [15]. STIC was proposed to be a precursor to serous cancer and defined as a non-invasive lesion, recognized by the finding of morphologic atypia, increased proliferation, p53 overexpression and no stromal infiltration [16]. Simultaneously, "p53 signature" was defined as a focus of cells with strong nuclear p53 overexpression, but without increased proliferation or morphological abnormalities [15]. This is considered a precursor of STIC and consequently of high-grade serous carcinomas of the Fallopian tube [17]. In BSO specimens from women with BRCA1 or BRCA2 mutation, the rate of occult invasive carcinomas found at the time of prophylactic surgery ranges from $1.3 \%$ to $10 \%[1,10,14,18,19]$ and precursor lesions STIC and "p53 signature" have been identified in $1 \%-6.6 \%[14,18,19]$ and $11 \%-71 \%[16,20,21]$, respectively. Whether these premalignant lesions found in prophylactic specimens are an established risk factor for PSC is unknown.

In addition, although multiple molecular, pathological and clinical risk

*Corresponding author: Neda Stjepanovic, Department of Medical Oncology, Val d'Hebron University Hospital, P. Vall d'Hebron 119-129, 08035 Barcelona, Spain, Tel: 0034932746085; Fax: 0034932746059; E-mail: nstjepanovic@vhebron.net

Received October 08, 2015; Accepted November 20, 2015; Published November 27, 2015

Citation: Stjepanovic N, Carrasco E, Gadea N, Gil-Moreno A, Perez A, et al. (2015) Age of Salpingo-Oophorectomy and Risk of Peritoneal Carcinomatosis in Patients with a BRCA Mutation. J Mol Genet Med 7: 190 doi:10.4172/1747-0862.1000190

Copyright: ( 2015 Stjepanovic N, et al. This is an open-access article distributed under the terms of the Creative Commons Attribution License, which permits unrestricted use, distribution, and reproduction in any medium, provided the original author and source are credited 
Citation: Stjepanovic N, Carrasco E, Gadea N, Gil-Moreno A, Perez A, et al. (2015) Age of Salpingo-Oophorectomy and Risk of Peritoneal Carcinomatosis in Patients with a BRCA Mutation. J Mol Genet Med 7: 190 doi:10.4172/1747-0862.1000190

Page 2 of 6

factors for OVC and FTC have been established, specific risk factors for the potential development of PSC are unknown. Therefore, women with a BRCA germline mutation who undergo BSO are left with an undefined residual risk of a serious disseminated malignancy to the peritoneum.

Our aims were to describe the clinical, pathological and molecular characteristics of women with a BRCA germline mutation who underwent BSO, analyze the incidence of PSC after BSO, and identify clinical, pathological and molecular risk factors associated with PSC in our clinic-based cohort of BRCA1 and BRCA2 mutation carriers.

\section{Patients and Methods}

\section{Patients and follow-up}

Consecutive unselected 117 women with germline mutations in BRCA1 or BRCA2 genes who had undergone a BSO between April 2005 and September 2013 were identified from Vall d'Hebron High Risk Clinics database. Clinical data was obtained from the database and was completed with a detailed review of the medical records. Before undergoing surgery, women were evaluated by a gynaecologist for thorough gynaecological examination, transvaginal ultrasound and serum CA-125 in order to screen for potential papillary serous cancers. In the group of women who had previously undergone a unilateral salpingectomy or salpingo-oophorectomy with or without hysterectomy, completion of the contralateral salpingo-oophorectomy, oophorectomy or salpingectomy was performed at the time of knowing their BRCA status. For this group of women the date considered to represent BSO was the second surgery. All patients underwent BSO defined as resection of both ovaries and Fallopian tubes, and peritoneal washing was done in 105 patients. Annual clinical follow-up occurred in patients who did not have prophylactic mastectomy in addition to BSO while patients who underwent prophylactic mastectomy and BSO had biannual follow up. Age and cause of death were obtained from medical records. The diagnosis of PSC during follow-up was based on the Gynecology Oncology Group (GOG) criteria for primary peritoneal carcinomas [22], which states that all cases of serous peritoneal cancer are considered to be primary peritoneal cancer if the ovarian component is nonexistent, i.e. because it had previously been removed. All women signed informed consent approved by the Institutional Review Board for participation in clinical research before enrolling in this analysis.

\section{Pathological review and immunohistochemistry staining}

After salpingo-oophorectomy, the ovaries and Fallopian tubes were submitted for histological examination. Protocol for prophylactic salpingo-oophorectomies including "sectioning and extensively examining the fimbriated end (SEE-FIM)" [23] was performed in patients whose specimens were analyzed in our center after 2006. Eight patients had been operated before 2006 and followed the standard histological examination at that time. Hematoxylin/eosin stained sections were reviewed by two independent gynaecological pathologists for the presence of non-invasive lesions and invasive carcinomas of ovaries and/or Fallopian tubes, according to standardized criteria. Immunohistochemistry for p53 and Ki67 using standard techniques were used in all cases of STIC and invasive carcinomas, and to 58 unselected women without macroscopic pathological abnormalities.

The presence of a "p53 signature" was defined as nuclear overexpression of $\mathrm{p} 53$ in a focus of 12 or more consecutive fallopian epithelium cells in absence of atypia and increased proliferation (Figure 1). Malignant lesions of the Fallopian tube were classified as noninvasive and invasive. The non-invasive lesions correspond to STICs defined as cytologic atypia, positive staining for $\mathrm{p} 53$ and proliferative activity (Ki-67 stain) in the epithelial layer of the Fallopian tubes (Figure 2). Invasive lesions were classified using the FIGO staging used for primary Fallopian tubal carcinomas.
$1 \mathrm{a}$

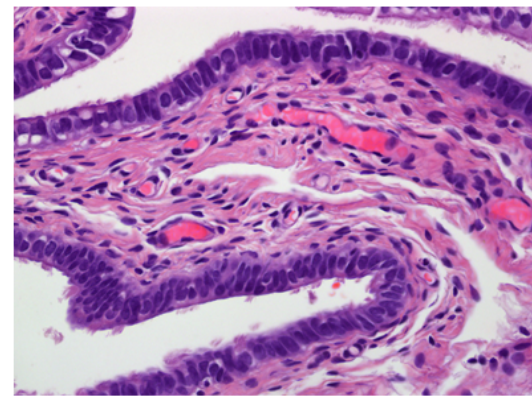

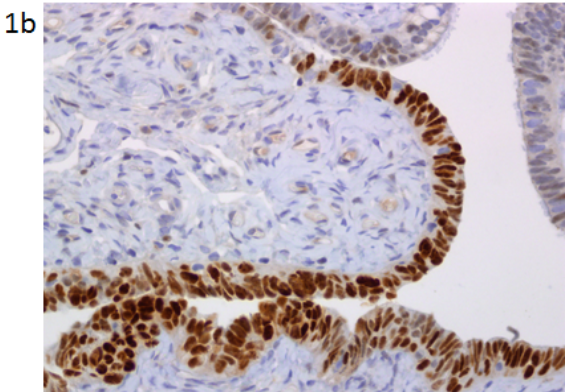

Figure 1: Fallopian tube epithelium with p53 signature. (a) Hematoxylin/eosin stain without morphological alterations; (b) p53 immunostain with nuclear overexpression of p53 in more than 13 consecutive cells.

$2 a$

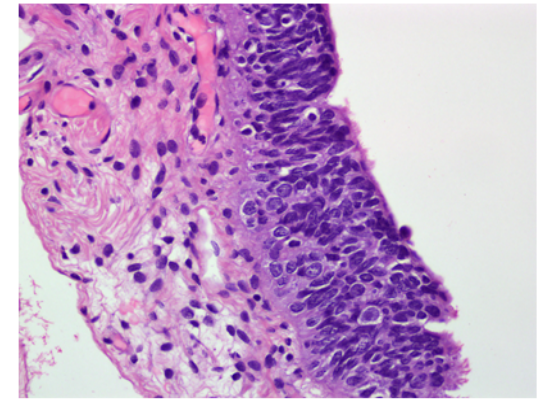

$2 \mathrm{~b}$

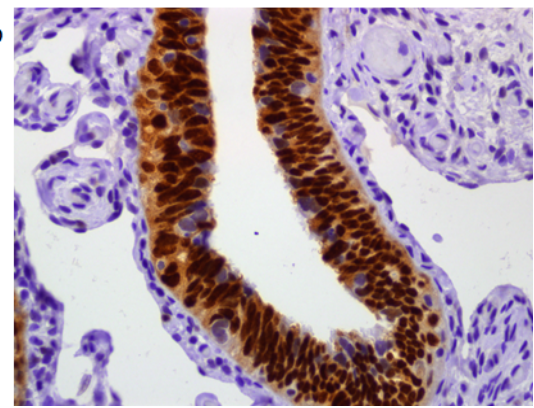

Figure 2: Fallopian tube with serous tubal intraepithelial carcinoma (STIC). (a) Hematoxylin/eosin stain with pseudostratification and nuclear atypia, without exceeding the basal lamina; (b) p53 immunostain with p53 nuclear overexpression in the area of STIC. 


\section{Data analysis}

First, the overall incidence of occult invasive carcinomas and precursor lesions in the BSO specimen was determined. Women with pathological or molecular abnormalities (FTC, STIC or "p53 signature") in the BSO specimen were considered as cases and women without abnormalities were considered controls. Cases and controls were compared for the following clinical risk factors: age of menarche, age of menopause, age at BSO, mutation (BRCA1 vs. BRCA2), oral contraceptive (OC) use (yes/no, and duration of use), parity, age at first birth, breastfeeding (yes/no, and duration), hormone replacement therapy use (yes/no), Body Mass Index (BMI), personal history of breast cancer (yes/no), familial history of breast, prostate and ovarian cancer (yes/no), preoperative transvaginal ultrasound control (normal/ abnormal findings) and preoperative CA-125 levels.

Secondly, we established the overall incidence of PSC after BSO, considering as cases women who developed PSC after BSO with women who did not as controls. Finally, in order to answer the primary question of our study, cases and controls for PSC were compared for the same clinical risk factors mentioned above, as well as pathological risk factors (presence or absence of FTC or STIC), and molecular risk factors (presence or absence of "p53 signature").

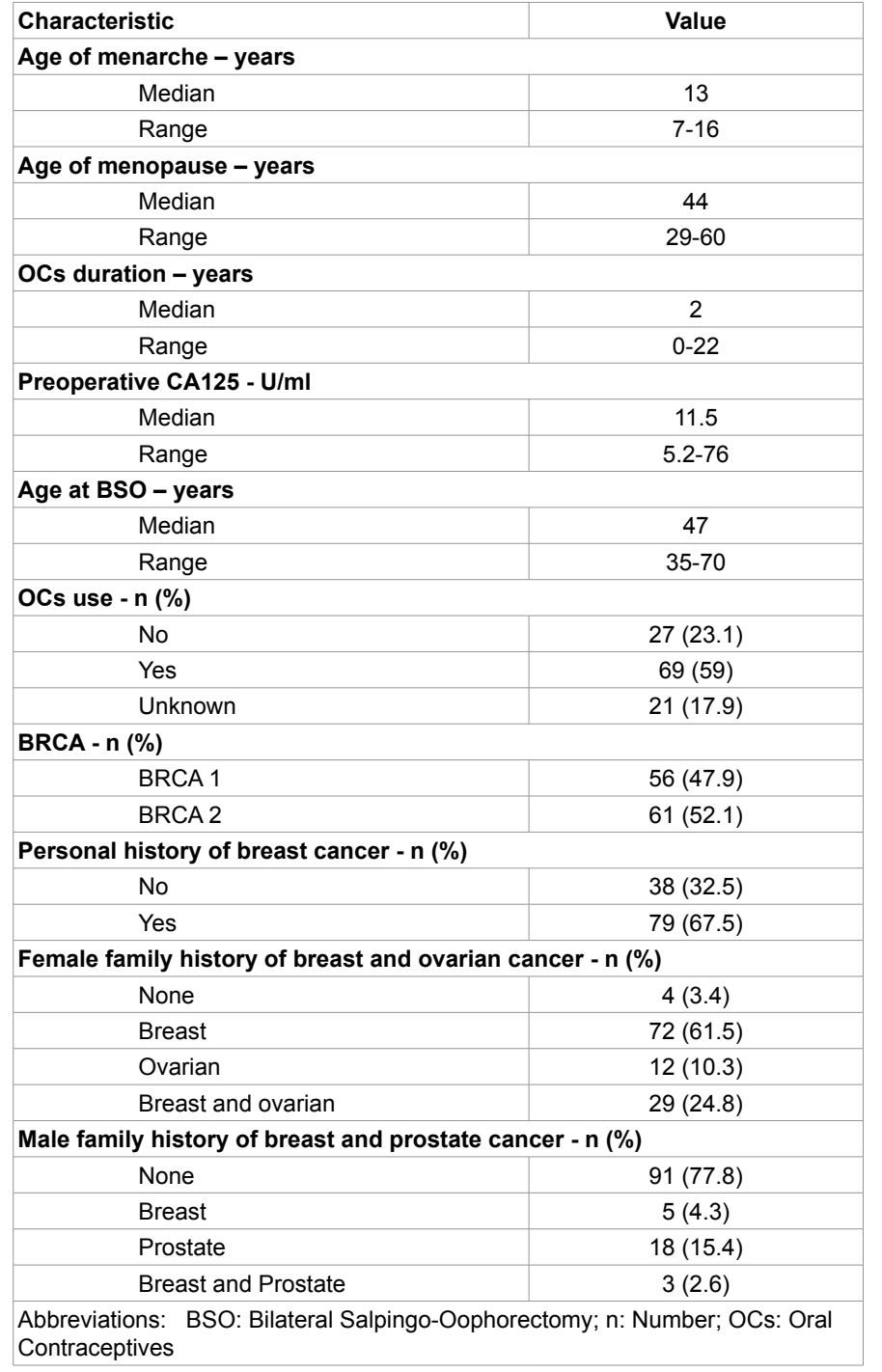

Table 1: Population clinical characteristics of the 117 study patients.
Student's $\mathrm{t}$ test was used to test for statistical significance for continuous variables and Fisher exact test was used for categorical variables. Statistical analysis was performed with SPSS v19.

\section{Results}

From April 2005 to September 2013, we identified 117 consecutive women with a BRCA germline mutation (48\% BRCA1 and 52\% BRCA2) who had undergone BSO. The median age at BSO was 47 years (range 35 - 70 years); 23 women underwent surgery aged 40 or younger $(20 \%)$. Other relevant clinical characteristics are depicted in Table 1. Bilateral salpingo-oophorectomy with prophylactic intention was performed in 106 patients, five patients underwent hysterectomy with BSO (two prophylactic and three for benign pathologies), while six patients had a prior incomplete surgery for benign pathologies, which required second oophorectomy and/or salpingectomy. Median follow-up after surgery was 33 months. Of the 117 women who underwent salpingooophorectomy, one $(0.8 \%)$ woman was found to have an occult FTC, two (1.7\%) presented with STIC and 114 (97.4\%) women did not have any pathologic lesion in the $\mathrm{BSO}$ specimen. Peritoneal washings were done in 105 patients; all were negative for malignant cells. Among the 58 patients whose BSO specimens were analyzed for the presence of "p53 signature", six (10.3\%) were positive. None of the 23 patients who underwent surgery aged 40 or younger had any abnormal pathologic findings.

The woman diagnosed with occult invasive FTC was a BRCA1 mutation carrier who underwent prophylactic BSO at the age of 69. Her preoperative CA-125 levels were $20.3 \mathrm{U} / \mathrm{mL}$, preoperative gynaecologic examination and transvaginal ultrasound were normal. She had a family history of breast and prostate carcinomas, but no personal history of any other malignancy. The FTC was detected on microscopic pathological examination and staged as a FIGO stage IA, grade 3 carcinoma. She completed cytoreductive surgery with optimal debulking, post-operative adjuvant chemotherapy and remains free of disease 19 months later.

One patient diagnosed with STIC was a BRCA1 mutation carrier, a mother of three children, had no personal history of cancer and a normal gynaecological examination, ultrasound and CA-125 (14.6 U/ $\mathrm{mL}$ ) prior to surgery. She had a family history of ovarian carcinoma and underwent prophylactic BSO at the age of 51. She remains alive and free of disease 7 years later. The second patient diagnosed with STIC was a BRCA2 mutation carrier, multiparous with five children, no personal history of cancer and a family history of breast tumors, who underwent BSO at the age of 63. Gynaecological examination prior to prophylactic surgery showed a simple cyst and a CA-125 level of 23 $\mathrm{U} / \mathrm{mL}$. Examination of the BSO specimen showed STIC. Two years after the preventive surgery she developed PSC stage IV with pleural effusion. After 6 cycles of neoadjuvant chemotherapy she underwent cytoreductive surgery with optimal debulking. She remains without evidence of disease twenty-six months after surgery.

Patients with histopathological abnormalities (FTC and STIC) were compared with patients without histopathological abnormalities regarding several clinical risk factors (Table 2). Two predictors for the presence of microscopic non-invasive or invasive lesions were identified: the age of menopause and the duration of past OC therapy. The mean age of menopause for women with normal epithelium was 43.9 years (29.8\% had spontaneous, $28.1 \%$ chemotherapy-induced and $42.1 \%$ surgery-induced menopause), and for women with STIC and FTC 52.7 years $(66.6 \%$ spontaneous menopause and $33.3 \%$ surgery induced $(\mathrm{p}=0.007)$. The mean reported duration of OC treatment was 
3.9 years for women with normal epithelium and 0.1 years for women with STIC and FTC $(\mathrm{p}<0.001)$. Of the six patients with "p53 signature", four were carriers of a BRCA2 mutation while the other two were BRCA1 mutation carriers. Their mean age at BSO was 50.8 years (range 42 - 63). Cases of patients positive for "p53 signature" and their controls were also compared for clinical risk factors (data not shown), but no predictors were identified.

During follow-up two patients $(1.7 \%$ of the overall cohort) developed PSC after BSO (Table 3). Both were BRCA2 mutation

\begin{tabular}{|c|c|c|c|}
\hline & $\begin{array}{c}\text { STIC / FTC } \\
\text { present } \\
(n=3)\end{array}$ & $\begin{array}{c}\text { STIC / FTC } \\
\text { absent } \\
(n=114)\end{array}$ & p-value ${ }^{1}$ \\
\hline Age menarche - years & $14.0(1.7)$ & $12.5(1.5)$ & 0.281 \\
\hline Age menopause - years & $52.7(2.1)$ & $43.9(6.0)$ & 0.007 \\
\hline OCs duration - years & $0.1(0.1)$ & $3.9(4.6)$ & $<0.001$ \\
\hline Age at BSO - years & $61.0(9.2)$ & $48.6(8.5)$ & 0.140 \\
\hline Age at first birth - years & $23.7(1.5)$ & $26.4(4.7)$ & 0.063 \\
\hline \multicolumn{3}{|l|}{ BRCA - $n$} & p-value ${ }^{2}$ \\
\hline BRCA1 & 2 & 54 & \multirow{2}{*}{0.606} \\
\hline BRCA2 & 1 & 60 & \\
\hline \multicolumn{4}{|c|}{ Family history of ovarian cancer - $n$} \\
\hline No & 2 & 74 & \multirow{2}{*}{1.000} \\
\hline Yes & 1 & 40 & \\
\hline \multicolumn{4}{|c|}{ Personal history of breast cancer - $n$} \\
\hline No & 3 & 35 & \multirow{2}{*}{0.032} \\
\hline Yes & 0 & 79 & \\
\hline
\end{tabular}

Abbreviations: BSO: Prophylactic Bilateral Salpingo-Oophorectomy; FTC: Fallopian Tube Carcinoma; n: Number; OCs: Oral Contraceptives; STIC: Serous Tubal Intraepithelial Carcinoma. Values are expressed as mean (+/- standard deviation), except otherwise stated. 1. T-d'Student test; 2. Fisher's exact test.

Table 2: STIC/FTC risk factors. carriers. One is the aforementioned patient with a history of a STIC lesion at her BSO specimen. The second patient underwent hysterectomy with bilateral salpingo-oophorectomy at the age of 64 due to an endometrial polyp. Her BRCA status was not known at the time of the surgery, histopathological examination of the specimen was done according to the historical standards and no evidence of malignancy was found. This patient was nulliparous, she had a personal history of bilateral breast carcinoma at the ages of 52 and 57 years and a family history of prostate cancer. She developed stage IIIC PSC nine years after bilateral salpingo-oophorectomy. She was treated with uncompleted staging debulking surgery consisting of omentectomy and loco-regional lymphadenectomy, but without pelvic and paraaortic lymphadenectomy. No macroscopic residual disease was noted. She completed adjuvant chemotherapy, but recurred 7 months later, at which time she was treated with 2 lines of palliative chemotherapy until she passed away 37 months after the recurrence of PSC.

Cases who developed PSC and those who did not were compared for clinical, pathological and molecular risk factors (Table 4). Age at $\mathrm{BSO}$ was the only significant predictor for PSC after BSO. The mean age of BSO for women who developed PSC was 63.5 years and 48.6 for the control group $(\mathrm{p}<0.001)$.

\section{Discussion}

From a cohort of 117 BRCA1 and BRCA2 germline mutation carriers who underwent salpingo-oophorectomy, one occult invasive tumor of the Fallopian Tube ( $0.8 \%)$ and two STICs (1.7\%) were detected in the BSO specimens. For these two types of lesions, younger age at menopause and longer use of OCs were found to be protective. Six "p53 signatures" (10.3\%) in the 58 BSO specimens analyzed were detected, but no risk factors were significantly associated with their presence. No ovarian carcinomas were diagnosed in BSO specimens. With a medium

\begin{tabular}{|c|c|c|c|c|c|c|c|c|c|c|}
\hline Pat. & BRCA status & $\begin{array}{c}\text { Age BSO } \\
\text { (years) }\end{array}$ & $\begin{array}{l}\text { Diagnosis } \\
\text { (stage) }\end{array}$ & PSC & $\begin{array}{c}\text { Follow-up* } \\
\text { (months) }\end{array}$ & $\begin{array}{c}\text { Parity } \\
\text { (number) }\end{array}$ & $\begin{array}{c}\text { OCs } \\
\text { (years) }\end{array}$ & $\begin{array}{l}\text { Menop. } \\
\text { (age) }\end{array}$ & $\begin{array}{l}\text { Personal } \\
\text { cancer } \\
\text { history }\end{array}$ & $\begin{array}{l}\text { Familial } \\
\text { cancer } \\
\text { history }\end{array}$ \\
\hline 1 & $\begin{array}{l}\text { BRCA1 } \\
\text { (c.5251C>T) }\end{array}$ & 69 & FTC (IA) & No & 5 & 2 & 0 & 52 & - & $\begin{array}{l}\text { Breast, } \\
\text { Prostate }\end{array}$ \\
\hline 2 & $\begin{array}{l}\text { BRCA1 } \\
\text { (c.5214C>T) }\end{array}$ & 51 & STIC & No & 53 & 3 & 0,25 & 51 & - & Ovarian \\
\hline 3 & $\begin{array}{l}\text { BRCA2 } \\
\text { (c.2808_2811del4) }\end{array}$ & 63 & STIC & Yes & 47 & 5 & 0 & 55 & - & Breast \\
\hline 4 & $\begin{array}{l}\text { BRCA1 } \\
\text { (c.943_944ins10) }\end{array}$ & 46 & p53 sign. & No & 17 & 1 & 1 & 46 & - & Breast \\
\hline 5 & $\begin{array}{l}\text { BRCA2 } \\
\text { (c.9026_9030del5) }\end{array}$ & 52 & p53 sign. & No & 31 & 0 & 0 & 47 & Breast & Breast \\
\hline 6 & $\begin{array}{l}\text { BRCA2 } \\
\text { (c.541delT) }\end{array}$ & 51 & p53 sign. & No & 35 & 2 & UK & 42 & Breast & Breast \\
\hline 7 & $\begin{array}{l}\text { BRCA2 } \\
\text { (c.7984dupA) }\end{array}$ & 42 & p53 sign. & No & 16 & 1 & 2 & 42 & - & $\begin{array}{l}\text { Breast, } \\
\text { Ovarian }\end{array}$ \\
\hline 8 & $\begin{array}{l}\text { BRCA1 } \\
\text { (c.1687C>T) }\end{array}$ & 63 & p53 sign. & No & 1 & 3 & 10 & 57 & Breast & $\begin{array}{l}\text { Breast } \\
\text { Ovarian }\end{array}$ \\
\hline 9 & $\begin{array}{l}\text { BRCA2 } \\
(\mathrm{C} .3922 \mathrm{G}>\mathrm{T})\end{array}$ & 51 & p53 sign. & No & 7 & 2 & 15 & 50 & Breast & $\begin{array}{l}\text { Breast, } \\
\text { Prostate }\end{array}$ \\
\hline \multicolumn{11}{|c|}{ Patients diagnosed of PSC during the follow-up post BSO } \\
\hline Pac. & BRCA status & $\begin{array}{l}\text { Age BSO } \\
\text { (years) }\end{array}$ & \multicolumn{2}{|c|}{$\begin{array}{l}\text { PSC post BSO } \\
\quad \text { (years) }\end{array}$} & $\begin{array}{l}\text { Follow-un** } \\
\text { (months) }\end{array}$ & $\begin{array}{l}\text { Parity } \\
\text { (number) }\end{array}$ & $\begin{array}{c}\text { OCs } \\
\text { (years) }\end{array}$ & $\begin{array}{l}\text { Menop. } \\
\text { (age) }\end{array}$ & $\begin{array}{l}\text { Personal } \\
\text { cancer } \\
\text { history }\end{array}$ & $\begin{array}{l}\text { Familiar cancer } \\
\text { history }\end{array}$ \\
\hline 3 & $\begin{array}{l}\text { BRCA2 } \\
\text { (c.2808_2811del4) }\end{array}$ & 63 & \multicolumn{2}{|l|}{2} & 24 & 5 & 0 & 55 & No & Breast \\
\hline 10 & $\begin{array}{l}\text { BRCA2 } \\
\text { (c.9345>A, splicing) }\end{array}$ & 64 & \multicolumn{2}{|l|}{9} & 48 & 0 & 0 & 50 & Breast & Prostate \\
\hline
\end{tabular}

Abbreviations: BSO: Bilateral Salpingo-Oophorectomy; FTC: Fallopian Tube Carcinoma; OC: Oral Contraceptive; PSC: Peritoneal Serous Carcinoma; STIC: Serous Tubal Intraepithelial Carcinoma; UK: Unknown

Table 3: Patients with premalignant/malignant lesions or P53 signature in the BSO specimen. 


\begin{tabular}{|c|c|c|c|}
\hline & $\begin{array}{l}\text { PSC post BSO present } \\
(n=2)\end{array}$ & $\begin{array}{c}\text { PSC post BSO absent } \\
(n=115)\end{array}$ & p-value ${ }^{1}$ \\
\hline Age menarche - years & $12.5(3.5)$ & $12.6(1.5)$ & 0.979 \\
\hline Age menopause - years & $52.5(3.5)$ & $44.0(6.1)$ & 0.168 \\
\hline OCs duration - years & $0(-)$ & $3.8(4.6)$ & - \\
\hline Age at BSO - years & $63.5(0.7)$ & $48.6(8.6)$ & $<0.001$ \\
\hline Age at first birth - years & $24(-)$ & $26.4(4.7)$ & - \\
\hline \multicolumn{3}{|l|}{ BRCA - n (\%) } & p-value ${ }^{2}$ \\
\hline BRCA1 & 0 & 56 & \multirow{2}{*}{0.497} \\
\hline BRCA2 & 2 & 59 & \\
\hline \multicolumn{4}{|c|}{ Family history of ovarian carcinoma - $\mathrm{n}(\%)$} \\
\hline No & 2 & 74 & \multirow{2}{*}{0.541} \\
\hline Yes & 0 & 41 & \\
\hline \multicolumn{4}{|c|}{ Personal history of breast carcinoma - $\mathrm{n}(\%)$} \\
\hline No & 1 & 37 & \multirow{2}{*}{0.546} \\
\hline Yes & 1 & 78 & \\
\hline \multicolumn{4}{|c|}{ "P53 signature" in BSO - $\mathrm{n}(\%)$} \\
\hline No & 1 & 63 & \multirow{2}{*}{1.000} \\
\hline Yes & 0 & 6 & \\
\hline \multicolumn{4}{|l|}{ STIC in BSO - n (\%) } \\
\hline No & 1 & 114 & \multirow{2}{*}{0.034} \\
\hline Yes & 1 & 1 & \\
\hline
\end{tabular}

follow-up of 33 months, the incidence of PSC after BSO was $1.7 \%$ (2/117 patients), with a statistically significant relationship between older age at BSO and PSC. None of the abnormal findings from the BSO specimens were suspected before or at the time of the surgery; they were only discovered at microscopic examination. Neither transvaginal examination nor serum CA-125 level were sufficient to detect the described precursor or malignant lesions. There was only one patient with abnormal findings during the preoperative period who was then diagnosed with ovarian carcinoma, and therefore not included in the current analysis.

While the incidence of STIC in our study is in concordance with previous reports, the incidence of occult invasive carcinomas is slightly lower. Callahan et al. [14] reported 4 occult invasive carcinomas in a cohort of 122 BRCA1 and BRCA2 mutation carriers who underwent BSO with a median age of 46.5 years. In this study all women whose Fallopian tubes harbored occult invasive carcinomas were $\geq 44$ years of age. In contrast Retisma et al. [18] reported 4 cases of invasive occult carcinomas in a larger cohort of 308 BRCA mutation carriers (188 BRCA, 115 BRCA2 and 5 with variants of unknown significance) who underwent $\mathrm{BSO}$ at a median age of 44 years with pathogenic findings present in women older than 40 years of age. Since the median age at BSO and the age of discovering malignant findings $(\geq 40)$ was similar in these studies and in our cohort, we believe that the differences in incidence are not significant and can be attributed to the relatively small sample size of our study. In regards to "p53 signature", the frequency observed in our study is similar to that reported in the biggest cohort of BRCA carriers who underwent BSO [21], but lower than other smaller series $[16,20]$.

The two clinical factors identified in our analysis were associated with a higher risk of FTC and STIC. These were older age at menopause and a shorter use of OCs. Interestingly, both factors are related to a larger number of ovulations. In fact, there is evidence associating higher incidence of premalignant non-invasive lesions with older age at BSO, higher BMI, shorter use of OCs, lower parity and older age at first childbirth. These are all factors associated with ovulation. These results concur with other studies that found that parity and OC use, both related to a lower number of ovulations, were associated with a decreased risk of invasive lesions [24]. In summary, there seems to be a plausible amount of clinical evidence supporting a relationship between ovulation and premalignant ovarian lesions in BRCA mutation carriers. Consequently, medical interventions aimed at decreasing the number of ovulations may help to prevent ovarian cancer in this high risk genetic population, as has already been shown by McLaughlin et al. [25] and Iodice et al. [26]. The study by Domchek et al. [10], which enrolled 993 BRCA1 and BRCA2 mutation carriers who underwent BSO, found the incidence of PSC after BSO to be $1 \%$, which is similar to our findings. It is of interest that in our cohort PSC was diagnosed in two BRCA2 carriers, while the majority of the cases reported in the literature are BRCA1 carriers. Foulkes et al. also report two BRCA2 women who developed PSC [27]. Our cohort was not large enough to conclude that BRCA2 carriers have a greater risk of developing PSC than BRCA1 carriers since a likely explanation for our results is the large number of BRCA2 carriers in our cohort. Therefore, this observation requires further validation in larger cohorts.

The results of our study suggest that the risk of developing PSC post BSO increases with older age of prophylactic surgery. The two patients who developed PSC underwent salpingo-oophorectomy at 63 and 64 years.

There are some limitations of our study. Not all specimens were examined using the SEE-FIM protocol, which was only established from 2006 onwards. Specifically, one of the two patients with PSC during follow-up underwent hysterectomy and bilateral salpingoophorectomy for benign pathology in 2001 thus SEE-FIM examination of the surgical specimen was not performed. Other limitations include the retrospective nature of the study, such that the type and clinical indication for the surgery was not always clear. The sample size for analysis of p53 signature is small (58 patients, only half the cohort), as immunohistochemical staining in patients who underwent surgery 
before 2006 was not done. We were unable to determine some potential confounders like age at first childbirth. Finally, overall median followup is short with 45 women from the cohort not reaching the time point at which the first PSC case occurred (two years post BSO). This might therefore cause underestimation of the incidence of PSC.

In conclusion, our analysis suggests that an older age at BSO is related to an increased risk of PSC in BRCA mutation carriers. This data, if confirmed in a larger cohort, may add another piece of evidence to the question of when women with a BRCA germline mutation should undergo BSO to maximize clinical benefit.

\section{References}

1. Levine DA, Argenta PA, Yee CJ, Marshall DS, Olvera N, et al. (2003) Fallopian tube and primary peritoneal carcinomas associated with BRCA mutations. J Clin Oncol 21: 4222-4227.

2. Chen S, Parmigiani G (2007) Meta-analysis of BRCA1 and BRCA2 penetrance. $\mathrm{J}$ Clin Oncol 25: 1329-1333

3. Alsop K, Fereday S, Meldrum C, deFazio A, Emmanuel C, et al. (2012) BRCA mutation frequency and patterns of treatment response in BRCA mutationpositive women with ovarian cancer: a report from the Australian Ovarian Cancer Study Group. Journal of Clinical Oncology: Official Journal of the American Society of Clinical Oncology 30: 2654-2663.

4. Burke W, Daly M, Garber J, Botkin J, Kahn MJ, et al. (1997) Recommendations for follow-up care of individuals with an inherited predisposition to cancer. II. BRCA1 and BRCA2. Cancer Genetics Studies Consortium. JAMA 277: $997-$ 1003.

5. Burke W, Petersen G, Lynch P, Botkin J, Daly M, et al. (1997) Recommendations for follow-up care of individuals with an inherited predisposition to cancer I. Hereditary nonpolyposis colon cancer. Cancer Genetics Studies Consortium. JAMA 277: 915-919.

6. Hermsen BB, Olivier RI, Verheijen RH, van Beurden M, de Hullu JA, et al. (2007) No efficacy of annual gynaecological screening in BRCA1/2 mutation carriers; an observational follow-up study. Br J Cancer 96: 1335-1342.

7. Meeuwissen PA, Seynaeve C, Brekelmans CT, Meijers-Heijboer HJ, Klijn JG et al. (2005) Outcome of surveillance and prophylactic salpingo-oophorectomy in asymptomatic women at high risk for ovarian cancer. Gynecol Oncol 97: 476-482.

8. Rosenthal AN, Fraser L, Manchanda R, Badman P, Philpott S, et al. (2013) Results of annual screening in phase I of the United Kingdom familial ovarian cancer screening study highlight the need for strict adherence to screening schedule. Journal of clinical oncology: Official Journal of the American Society of Clinical Oncology 31: 49-57.

9. Finch AP, Lubinski J, Møller P, Singer CF, Karlan B, et al. (2014) Impact of oophorectomy on cancer incidence and mortality in women with a BRCA1 or BRCA2 mutation. J Clin Oncol 32: 1547-1553.

10. Domchek SM, Friebel TM, Singer CF, Evans DG, Lynch HT, et al. (2010) Association of risk-reducing surgery in BRCA1 or BRCA2 mutation carriers with cancer risk and mortality. JAMA 304: 967-975.

11. Finch A, Beiner M, Lubinski J, Lynch HT, Moller P, et al. (2006) Salpingooophorectomy and the risk of ovarian, fallopian tube, and peritoneal cancers in women with a BRCA1 or BRCA2 Mutation. JAMA 296: 185-192.
12. Rebbeck TR, Kauff ND, Domchek SM (2009) Meta-analysis of risk reduction estimates associated with risk-reducing salpingo-oophorectomy in BRCA1 or BRCA2 mutation carriers. J Natl Cancer Inst 101: 80-87.

13. Casey MJ, Synder C, Bewtra C, Narod SA, Watson P, et al. (2005) Intraabdominal carcinomatosis after prophylactic oophorectomy in women of hereditary breast ovarian cancer syndrome kindreds associated with BRCA1 and BRCA2 mutations. Gynecol Oncol 97: 457-467.

14. Callahan MJ, Crum CP, Medeiros F, Kindelberger DW, Elvin JA, et al. (2007) Primary fallopian tube malignancies in BRCA-positive women undergoing surgery for ovarian cancer risk reduction. Journal of Clinical Oncology: Official Journal of the American Society of Clinical Oncology 25: 3985-3990.

15. Lee Y, Miron A, Drapkin R, Nucci MR, Medeiros F, et al. (2007) A candidate precursor to serous carcinoma that originates in the distal fallopian tube. $J$ Pathol 211: 26-35

16. Folkins AK, Jarboe EA, Saleemuddin A, Lee Y, Callahan MJ, et al. (2008) A candidate precursor to pelvic serous cancer (p53 signature) and its prevalence in ovaries and fallopian tubes from women with BRCA mutations. Gynecol Oncol 109: 168-173.

17. Kindelberger DW, Lee Y, Miron A, Hirsch MS, Feltmate C, et al. (2007) Intraepithelial carcinoma of the fimbria and pelvic serous carcinoma: Evidence for a causal relationship. Am J Surg Pathol 31: 161-169.

18. Reitsma W, de Bock GH, Oosterwijk JC, Bart J, Hollema H, et al. (2013) Support of the 'fallopian tube hypothesis' in a prospective series of risk-reducing salpingo-oophorectomy specimens. Eur J Cancer 49: 132-141.

19. Leeper K, Garcia R, Swisher E, Goff B, Greer B, et al. (2002) Pathologic findings in prophylactic oophorectomy specimens in high-risk women. Gynecol Oncol 87: 52-56.

20. Mehra KK, Chang MC, Folkins AK, Raho CJ, Lima JF, et al. (2011) The impact of tissue block sampling on the detection of p53 signatures in fallopian tubes from women with BRCA 1 or 2 mutations (BRCA+) and controls. Mod Pathol 24: 152-156.

21. Shaw PA, Rouzbahman M, Pizer ES, Pintilie M, Begley H (2009) Candidate serous cancer precursors in fallopian tube epithelium of BRCA1/2 mutation carriers. Mod Pathol 22: 1133-1138.

22. Bloss JD, Liao SY, Buller RE, Manetta A, Berman ML, et al. (1993) Extraovarian peritoneal serous papillary carcinoma: a case-control retrospective comparison to papillary adenocarcinoma of the ovary. Gynecol Oncol 50: 347-351.

23. Medeiros F, Muto MG, Lee Y, Elvin JA, Callahan MJ, et al. (2006) The tubal fimbria is a preferred site for early adenocarcinoma in women with familial ovarian cancer syndrome. Am J Surg Pathol 30: 230-236.

24. Vicus D, Finch A, Rosen B, Fan I, Bradley L, et al. (2010) Risk factors for carcinoma of the fallopian tube in women with and without a germline BRCA mutation. Gynecol Oncol 118: 155-159.

25. McLaughlin JR, Risch HA, Lubinski J, Moller P, Ghadirian P, et al. (2007) Reproductive risk factors for ovarian cancer in carriers of BRCA1 or BRCA2 mutations: a case-control study. Lancet Oncol 8: 26-34.

26. lodice S, Barile M, Rotmensz N, Feroce I, Bonanni B, et al. (2010) Oral contraceptive use and breast or ovarian cancer risk in BRCA1/2 carriers: meta-analysis. Eur J Cancer 46: 2275-2284.

27. Foulkes WD, Narod SA, Swenerton K, Panabaker K, Gilbert L (2003) Re Gynecologic surgeries and risk of ovarian cancer in women with BRCA1 and BRCA2 Ashkenazi founder mutations: an Israeli population-based case-control study. J Natl Cancer Inst 95: 1640. 